\title{
A pressure indicator for the impact of Iberian wild goat on moss and soils in a Mediterranean climate
}

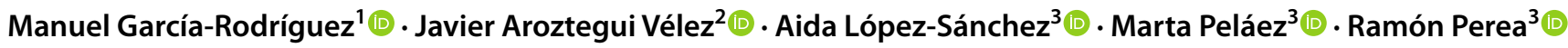

Received: 28 May 2021 / Accepted: 30 October 2021 / Published online: 21 November 2021

(c) The Author(s) 2021

\begin{abstract}
In the Sierra de Guadarrama National Park (central Spain), the population of Iberian wild goat, also known as Spanish ibex (Capra pyrenaica) has grown strongly since its reintroduction three decades ago. The plant community is now under heavy browsing pressure due to this high population. A study of the presence of moss on rocks was used herein as the basis for the design of an indicator, named impact on mosses $(\mathrm{im})$, to describe the environmental pressure exerted by the Iberian wild goat in terms of moss removal. Granite and gneiss zones at medium altitudes with continental Mediterranean climate are the most suitable areas for successful application of the indicator. The hypotheses to test are: (1) the indicator will discriminate between areas with different wild goat pressure levels, (2) wild goat pressure will explain a high proportion of moss loss variance, and (3) the im indicator will be useful to establish a mathematical model between wild goat pressure and moss loss. The proposed indicator was analyzed using both statistical and data science techniques. The results support the mentioned hypotheses. Specifically, statistically significant differences were found regarding the impact on mosses between areas with different levels of Iberian wild goat pressure. Thus, a high proportion of the variance was associated with wild goat pressure (80\% for high-pressure areas, $56 \%$ for low-pressure areas). A modified parabolic function was fit to express the relationship between Iberian wild goat pressure and impact on mosses. In conclusion, the $\mathrm{im}$ indicator was shown to be a useful tool to assess pressure due to Iberian wild goat. Therefore, im can help assess and manage Iberian wild goat populations and determine their sustainable levels.
\end{abstract}

Keywords Spanish ibex $\cdot$ Moss cover $\cdot$ Soil degradation $\cdot$ Indicator analysis $\cdot$ Data science $\cdot$ Step quadratic function model

\section{Introduction}

For more than 30 years, the Iberian wild goat has been part of the Sierra de Guadarrama landscape. In 1990, 67 individuals of the subspecies Capra pyrenaica victoriae (Refoyo et al. 2015) were reintroduced and from the outset showed

Communicated by Mohamed Ksibi.

Manuel García-Rodríguez

manu.garo@ccia.uned.es

Javier Aroztegui Vélez

jarozteg@ucm.es

Aida López-Sánchez

aida.lopez@upm.es

Marta Peláez

marta.pelaez@upm.es

Ramón Perea

ramon.perea@upm.es healthy population growth, reaching 5403 animals in 2021 . The current population represents a density of over 52 ind $\mathrm{km}^{-2}$ (Refoyo et al. 2019), excessively high to be ecologically sustainable (Perea et al. 2015). For comparison, other wild populations of similar ungulates in Europe show densities of between 0.2 and 16 ind $\mathrm{km}^{-2}$ (Fandos et al. 2010; Armstrong and Seddon 2008).

1 Departamento de Ciencias Analíticas, Facultad de Ciencias, Universidad Nacional de Educación a Distancia (UNED), Urbanización Monte Rozas, Avda. Esparta s/n, Ctra. de Las Rozas al Escorial Km. 5, Las Rozas, 28232 Madrid, Spain

2 Departamento de Investigación y Psicología en Educación, Facultad de Psicología, Universidad Complutense de Madrid (UCM), Campus de Somosaguas, Pozuelo de Alarcón, 28223 Madrid, Spain

3 Departamento de Sistemas y Recursos Naturales, Universidad Politécnica de Madrid, Madrid, Spain 
The Iberian wild goat has been recorded as feeding on over 230 different plant species, including woody species, herbaceous plants, lichens, and mosses (Martínez 1992). The constant pressure exerted on the environment since their reintroduction has produced significant damage on woody plants (Perea et al. 2015), mosses, and soils. This results in an unbalanced and unsustainable relation (García-Rodríguez 2018). The impact of wild herbivores on woody plant species is relatively well studied and known (Stillman et al. 1997; Hui 2006; Rooney 2009; Perea et al. 2014). However, its effect on bryophytes growing in Mediterranean habitats on granites and gneisses remains largely unknown. The impact of wild ungulates on moss cover was found to be nonsignificant in environments with greater water availability and plant cover (Marozas et al. 2009). The present study focuses on an area with low water availability to check for a possible negative relationship between the abundance of Iberian wild goat and moss cover on rocks. Mosses may become an important food item when no alternative resources are available (Concostrina-Zubiri et al. 2014, 2017). In addition, as wild goats have excellent rock-climbing skills, their impact on moss cover may also be related to trampling and rock erosion.

The Spanish National Parks Act 30/2014 establishes the need to create a "Monitoring and Evaluation Plan of the National Parks Network." It also requires environmental indicators to be defined, enabling monitoring of changes in different biological, geological, and ecological parameters within these protected areas (PNSG 2020). A well-designed indicator explains processes through the synthesis of information from various sources and additionally provides support for better management decisions concerning these protected areas by public authorities. However, for such an indicator to be useful, it must exhibit certain characteristics (Dale and Beyeler 2001): it must be easy to measure, predictive, and sensitive to different stress levels, enabling improvement outcomes through management measures. It must also be integrative, covering key gradients in ecological systems such as vegetation and soil types, or geomorphological environments. However, since we cannot monitor all the components of an ecological system, we must identify a small number of indicators that characterize the most relevant parts of the system (Gaillard et al. 2008).

One important change in ecosystems produced by ungulates is soil and rock erosion (Concostrina-Zubiri et al. 2014, 2017). Elimination of vegetative cover because of browsing or trampling exposes soils and rocks to erosional forces, thereby creating unstable surfaces (Pegau 1970). Specifically, elimination of mosses implies the loss of the primary edaphic sustenance, which is required for more evolved soils. Furthermore, the disappearance of moss from rocky outcrops reduces their surface roughness, facilitating particle movement. Without mosses, water moving faster over rock surface increases hillside erosion around the outcrops. This favors unearthing of rock blocks and erosion of unconsolidated material. This process is more frequent in areas of steep slopes or in alpine environments where soil erosion can advance drastically (Evans, 1996). Earlier studies (García-Rodríguez 2015; García-Rodríguez et al. 2017) showed a good correlation between rock moss loss and soil erosion in surrounding areas. Therefore, in this study, we aimed to validate the indicator im (impact on mosses) to understand how Iberian wild goat population pressure affects rock mosses. That could help to monitor the magnitude of erosive processes throughout the national park.

The definition of the im indicator relies on the relationship between ungulate population pressure and moss loss in dry areas. Hypotheses will be linked to the im indicator features and its usefulness. We hypothesize that our im indicator will be able to:

(a) Distinguish between areas with different Iberian wild goat grazing pressure. An indicator unable to distinguish between areas with different grazing pressures would be useless.

(b) Accurately assess different impact degrees (high proportion of variance) between areas with different degrees of browsing pressure. An indicator that can accurately assess different areas will facilitate comparison among areas.

(c) Establish functional relationships of (which explain and predict) Iberian wild goat pressure effects. An indicator expressed as a function indicates the different strength of relationships at different variable levels, leading to accurate predictions.

\section{Materials and methods}

\section{Study area}

The Sierra de Guadarrama National Park (SGNP) is located in the Spanish Central Range that was formed during the Variscan Orogeny (Peinado et al. 1981). Intrusions of plutonic bodies in diverse phases occurred at the end of this period (Pérez-Soba and Villaseca 2010). After a long period of erosion, the Variscan Orogeny followed, defining different erosion surface levels (Pedraza 1978). Later, the Alpine Orogeny elevated the current Spanish Central Range, reactivating the Variscan fractures and creating a relief with horst and graben morphology.

Most materials present in the SGNP are granites and gneisses, which define various geomorphological environments (Pedraza et al. 2014). The landscape mainly includes elements comprising large exposed rock outcrops and mixed areas of large rock blocks standing in sandy substrates 
(Centeno 1989; García-Rodríguez 2015). It also includes other areas of loose materials deriving from alterations of the geological substrate. The SGNP shows a strong altitudinal gradient, with height ranging from around $900 \mathrm{~m}$ to slightly above $2400 \mathrm{~m}$ at the top of Peñalara Peak (Fig. 1).

The climate in the area is of continental Mediterranean type, with cold winters and hot dry summers. The climatic conditions vary markedly with altitude, with three zones showing different characteristics (Comunidad de Madrid 2010). The lowest zone lies between 900 and $1400 \mathrm{~m}$, with $750 \mathrm{~mm}$ annual average rainfall, annual average temperature of $10{ }^{\circ} \mathrm{C}$, and maximum and minimum of $28{ }^{\circ} \mathrm{C}$ in summer and $-6{ }^{\circ} \mathrm{C}$ in winter, respectively. Between $1400 \mathrm{~m}$ and $2000 \mathrm{~m}$, the annual average rainfall is around $950 \mathrm{~mm}$, with annual average temperature of $8{ }^{\circ} \mathrm{C}$ and average maximum and minimum temperature of $25^{\circ} \mathrm{C}$ in summer and $-8{ }^{\circ} \mathrm{C}$ in winter, respectively. Precipitation regularly falls as snow between December and April. In the highest mountain zone, above $2000 \mathrm{~m}$, the annual rainfall is highly variable, ranging from 1200 to over $1500 \mathrm{~mm}$ while the average annual temperature fluctuates from 6 to $7^{\circ} \mathrm{C}$, with a summer maximum of $22{ }^{\circ} \mathrm{C}$ and winter minimum of $-12{ }^{\circ} \mathrm{C}$. In this zone, precipitation usually falls as snow between November and May.

The vegetation in the SGNP comprises a wide variety of species showing an extraordinary degree of adaptation to the difficult rocky environment with poorly developed soils. This includes pastures and shrubs in the highest areas, and forests on the slopes and in the valleys below $1800 \mathrm{~m}$ (Morales 2003).

At least 323 moss species have been catalogued in the Sierra de Guadarrama (Blanco Castro and Acón Remacha 1984; Vicente and Ron 1989; Luna and Estébanez 2008), accounting for $12.6 \%$ of all the plant species in the Community of Madrid (Morales 2003). Some examples of common species in the Sierra de Guadarrama include (Lara et al. 2005): Andreaea rupestris, Brachythecium populeum, Bryum gemmiparum, Fissidens pusillus, Funaria convexa, Amblyodon dealbatus, and Encalypta streptocarpa.

The variety and richness of plant species in the Sierra de Guadarrama have provided a huge food source that has enabled the proliferation of the Iberian wild goat (Capra pyrenaica Schinz, 1838) in the absence of natural predators for more than two decades (Fig. 2).

\section{Impact of Iberian wild goat on mosses (im indicator)}

The proposed indicator assesses the disappearance of rock moss cover due to Iberian wild goat grazing and/ or trampling. Rocks cleared of moss due to Iberian wild goat presence exhibit pale areas indicating the exact distribution and surface area of the patches previously covered by mosses (Fig. 3). Lichen typically surrounds moss

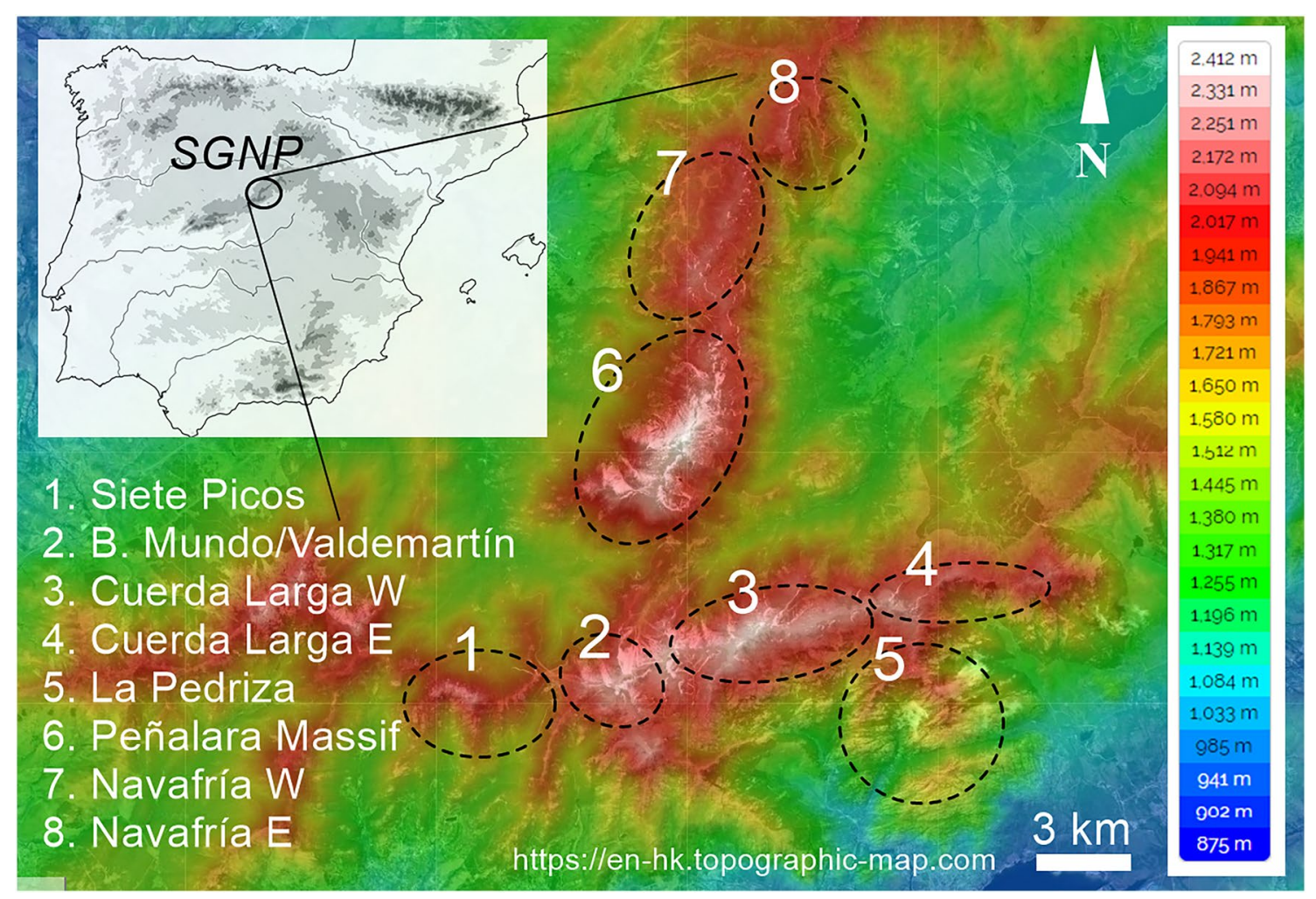

Fig. 1 Sierra de Guadarrama National Park locations, study areas, and altitudes 
Fig. 2 a Iberian wild goat grazing on mosses in an area where no other food resources remain (photo: Haday López Portillo). b Iberian wild goat group browsing on tender buds from a holm oak (Quercus ilex) growing in a rock crack (photo: Juan Luis Salcedo)

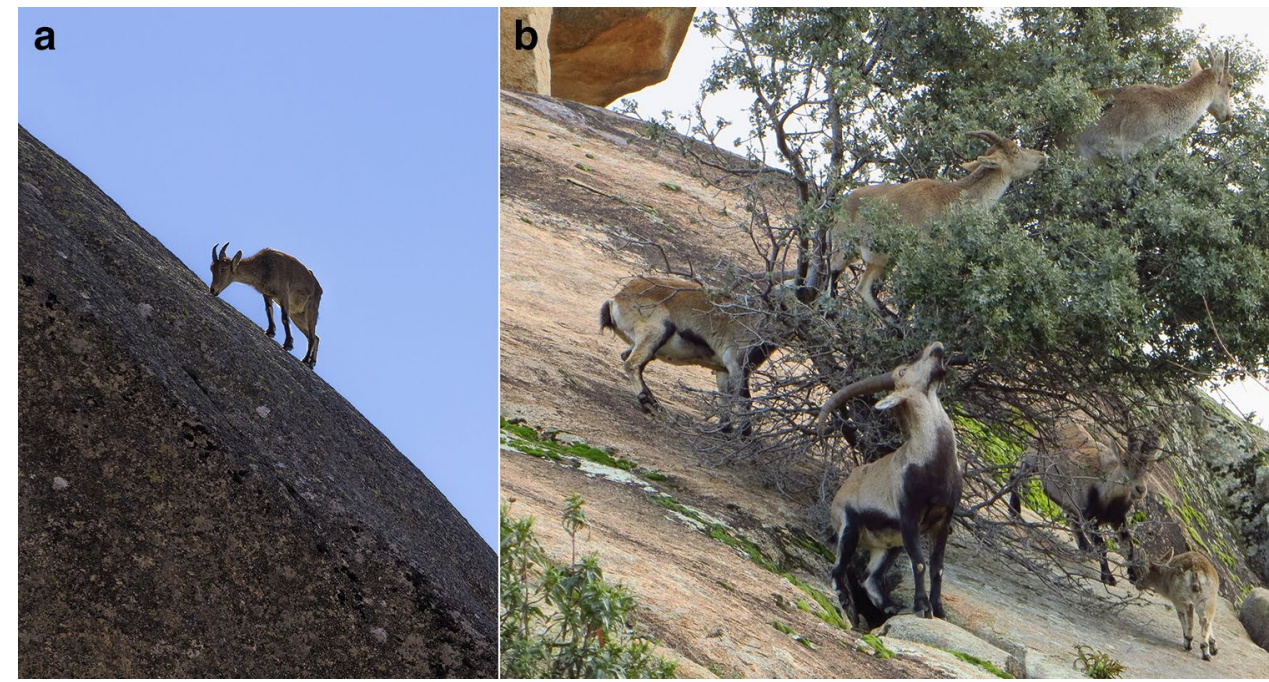

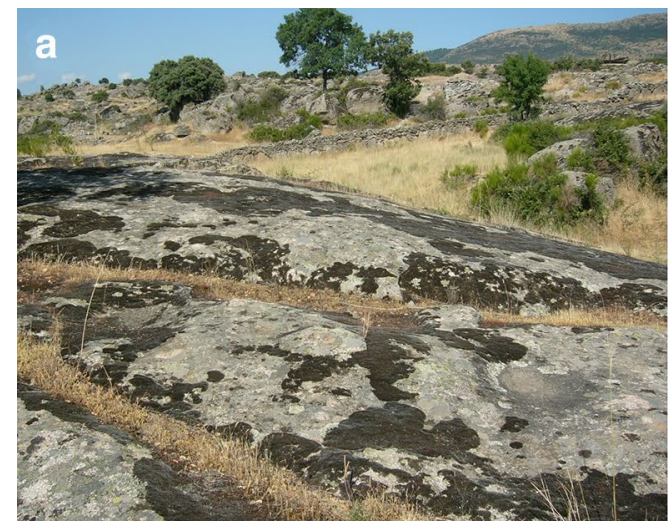

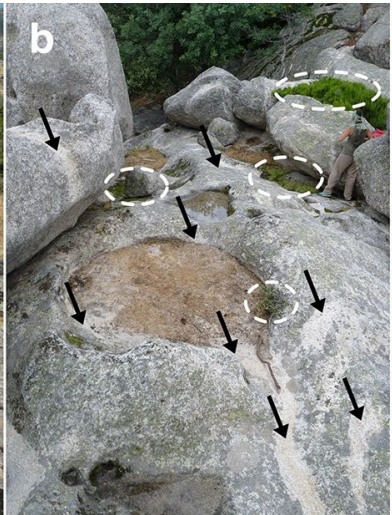

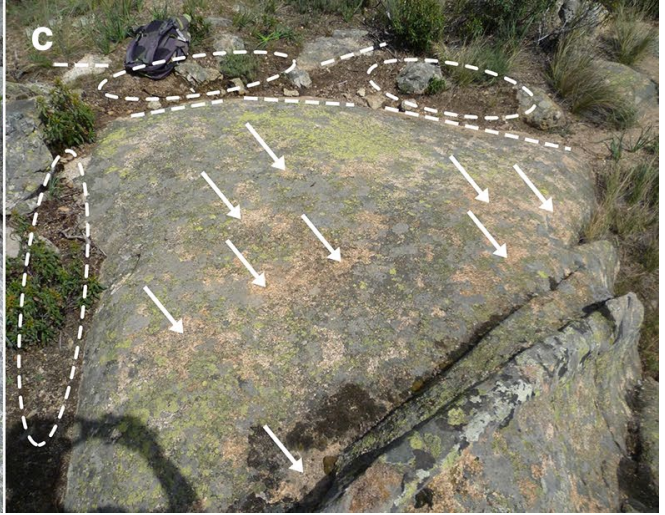

Fig. 3 a Granitoid domic surface outcrop with intact moss cover. This is a zone, near the SGNP border, located at an altitude of $900 \mathrm{~m}$, with no presence of Iberian wild goat. The im value at this area equals 0 , reflecting an absence of Iberian wild goat pressure. Around this rock outcrop, there are no signs of soil erosion or vegetation browsing. b, $\mathbf{c}$ Granitoid outcrops at La Pedriza, where $90 \%$ of moss has disappeared

areas. This facilitates the localization of disappeared moss patches areas, because their perimeter is clearly defined by a change in color and texture (García-Rodríguez 2015).

The value of the $i m$ indicator ranges from 0 to 1 . A value of 0 indicates no moss loss, linked to no pressure exerted by Iberian wild goat. A value of 1 indicates complete moss loss, because of grazing and/or trampling. Up to values of 0.2 , moss loss can be due to other natural causes. This threshold is derived from a group of areas with $i m$ values from 0 to 0.2 where there is no Iberian wild goat presence (Table 1).

Concerning the application of the $\mathrm{im}$ indicator, three geomorphological scenarios (Pedraza et al. 2014) were described: (a) rock outcrops, (b) screes, and (c) mixed terrain with both loose materials and rocks. Additionally, due to Iberian wild goat browsing (im around 0.9). Arrows indicate clear areas from where moss was eliminated. Ovals indicate woody plant browsing, soil elimination, and plenty of Iberian wild goat pellets. Dotted lines (photo c) signal limit perimeter banding of rock exposition due to regolith erosion

wide sandy areas of loose materials occur in the Sierra de Guadarrama, where the indicator cannot be applied.

\section{Rock outcrop (R)}

These are represented exclusively by granites and gneisses, covered by lichens and mosses (Fig. 4a). These rocks may form fractured and stepped walls, smooth rounded surfaces, or large rock blocks of tens of meters in size. Rock outcrops showing open fractures tend to be filled with muddy or sandy materials, leading to soil formation. This soil supports a wide range of plant species, including trees (Izquierdo 2007; Centeno and García-Rodríguez 2008). 
Table 1 Wild goat impact on mosses and number of pellet groups at each sampled site

\begin{tabular}{|c|c|c|c|c|c|c|c|c|c|}
\hline Location & LG & Id & $i m$ & $p g$ & Location & LG & Id & $i m$ & $p g$ \\
\hline La Pedriza & 1 & 1 & 0.00 & 1 & Bola Mundo/Valdemartín & 2 & 49 & NA & 17 \\
\hline La Pedriza & 1 & 2 & 0.50 & 0 & Bola Mundo/Valdemartín & 2 & 50 & NA & 12 \\
\hline La Pedriza & 1 & 3 & 0.70 & 2 & Bola Mundo/Valdemartín & 2 & 51 & NA & 6 \\
\hline La Pedriza & 1 & 4 & 0.60 & 5 & Bola Mundo/Valdemartín & 2 & 52 & NA & 17 \\
\hline La Pedriza & 1 & 5 & 0.85 & 21 & Bola Mundo/Valdemartín & 2 & 53 & 0.20 & 7 \\
\hline La Pedriza & 1 & 6 & 0.70 & 12 & Bola Mundo/Valdemartín & 2 & 54 & 0.60 & 15 \\
\hline La Pedriza & 1 & 7 & 0.80 & 8 & Siete Picos & 0 & 55 & 0.00 & 0 \\
\hline La Pedriza & 1 & 8 & 0.70 & 14 & Siete Picos & 0 & 56 & 0.10 & 0 \\
\hline La Pedriza & 1 & 9 & 0.60 & 6 & Siete Picos & 0 & 57 & 0.20 & 0 \\
\hline La Pedriza & 1 & 10 & 0.70 & 6 & Siete Picos & 0 & 58 & 0.10 & 0 \\
\hline Cuerda Larga West & 1 & 11 & 0.80 & 16 & Siete Picos & 0 & 59 & 0.00 & 0 \\
\hline Cuerda Larga West & 1 & 12 & 0.40 & 8 & Siete Picos & 0 & 60 & 0.10 & 0 \\
\hline Cuerda Larga West & 1 & 13 & 0.90 & 16 & Siete Picos & 0 & 61 & 0.00 & 0 \\
\hline Cuerda Larga West & 1 & 14 & 0.80 & 7 & Siete Picos & 0 & 62 & 0.10 & 0 \\
\hline Cuerda Larga West & 1 & 15 & 0.70 & 9 & Siete Picos & 0 & 63 & 0.05 & 0 \\
\hline Cuerda Larga West & 1 & 16 & 0.50 & 3 & Siete Picos & 0 & 64 & 0.05 & 0 \\
\hline Cuerda Larga West & 1 & 17 & 0.70 & 5 & Siete Picos & 0 & 65 & 0.05 & 0 \\
\hline Cuerda Larga West & 2 & 18 & NA & 4 & Siete Picos & 0 & 66 & 0.05 & 0 \\
\hline Cuerda Larga West & 2 & 19 & NA & 3 & Peñalara Massif & 3 & 67 & 0.10 & 3 \\
\hline Cuerda Larga West & 2 & 20 & NA & 21 & Peñalara Massif & 3 & 68 & NA & 2 \\
\hline Cuerda Larga West & 2 & 21 & NA & 3 & Peñalara Massif & 3 & 69 & NA & 3 \\
\hline Cuerda Larga West & 2 & 22 & NA & 35 & Peñalara Massif & 3 & 70 & NA & 10 \\
\hline Cuerda Larga West & 2 & 23 & NA & 5 & Peñalara Massif & 3 & 71 & NA & 32 \\
\hline Cuerda Larga West & 2 & 24 & NA & 11 & Peñalara Massif & 3 & 72 & NA & 10 \\
\hline Cuerda Larga West & 2 & 25 & NA & 33 & Peñalara Massif & 3 & 73 & NA & 11 \\
\hline Cuerda Larga West & 2 & 26 & NA & 5 & Peñalara Massif & 3 & 74 & NA & 2 \\
\hline Cuerda Larga West & 2 & 27 & NA & 10 & Peñalara Massif & 3 & 75 & NA & 7 \\
\hline Cuerda Larga West & 2 & 28 & NA & 15 & Peñalara Massif & 3 & 76 & NA & 0 \\
\hline Cuerda Larga West & 2 & 29 & 0.50 & 6 & Peñalara Massif & 3 & 77 & 0.00 & 0 \\
\hline Cuerda Larga West & 2 & 30 & 0.10 & 11 & Navafría West & 3 & 78 & NA & 1 \\
\hline Cuerda Larga West & 2 & 31 & NA & 6 & Navafría West & 3 & 79 & NA & 8 \\
\hline Cuerda Larga East & 2 & 32 & 0.20 & 8 & Navafría West & 3 & 80 & NA & 44 \\
\hline Cuerda Larga East & 2 & 33 & NA & 32 & Navafría West & 3 & 81 & NA & 26 \\
\hline Cuerda Larga East & 2 & 34 & NA & 8 & Navafría West & 3 & 82 & NA & 2 \\
\hline Cuerda Larga East & 2 & 35 & NA & 15 & Navafría West & 3 & 83 & NA & 20 \\
\hline Cuerda Larga East & 2 & 36 & NA & 17 & Navafría West & 3 & 84 & NA & 14 \\
\hline Cuerda Larga East & 2 & 37 & 0.20 & 0 & Navafría West & 3 & 85 & NA & 7 \\
\hline Cuerda Larga East & 2 & 38 & 0.40 & 2 & Navafría East & 0 & 86 & 0.00 & 0 \\
\hline Cuerda Larga East & 2 & 39 & 0.50 & 3 & Navafría East & 0 & 87 & 0.05 & 0 \\
\hline Cuerda Larga East & 2 & 40 & 0.70 & 20 & Navafría East & 0 & 88 & 0.00 & 0 \\
\hline Cuerda Larga East & 1 & 41 & 0.80 & 12 & Navafría East & 0 & 89 & 0.05 & 0 \\
\hline Cuerda Larga East & 1 & 42 & 0.80 & 4 & Navafría East & 0 & 90 & 0.10 & 0 \\
\hline Cuerda Larga East & 1 & 43 & NA & 4 & Navafría East & 0 & 91 & 0.20 & 0 \\
\hline Bola Mundo/Valdemartín & 2 & 44 & NA & 3 & Navafría East & 0 & 92 & 0.20 & 0 \\
\hline Bola Mundo/Valdemartín & 2 & 45 & NA & 18 & Navafría East & 0 & 93 & 0.05 & 0 \\
\hline Bola Mundo/Valdemartín & 2 & 46 & NA & 34 & Navafría East & 0 & 94 & 0.20 & 0 \\
\hline Bola Mundo/Valdemartín & 2 & 47 & NA & 13 & Navafría East & 0 & 95 & 0.05 & 0 \\
\hline Bola Mundo/Valdemartín & 2 & 48 & NA & 26 & & & & & \\
\hline
\end{tabular}

LG, location group, Id, identifier; im, impact on mosses; $p g$, pellet groups; NA, not available 


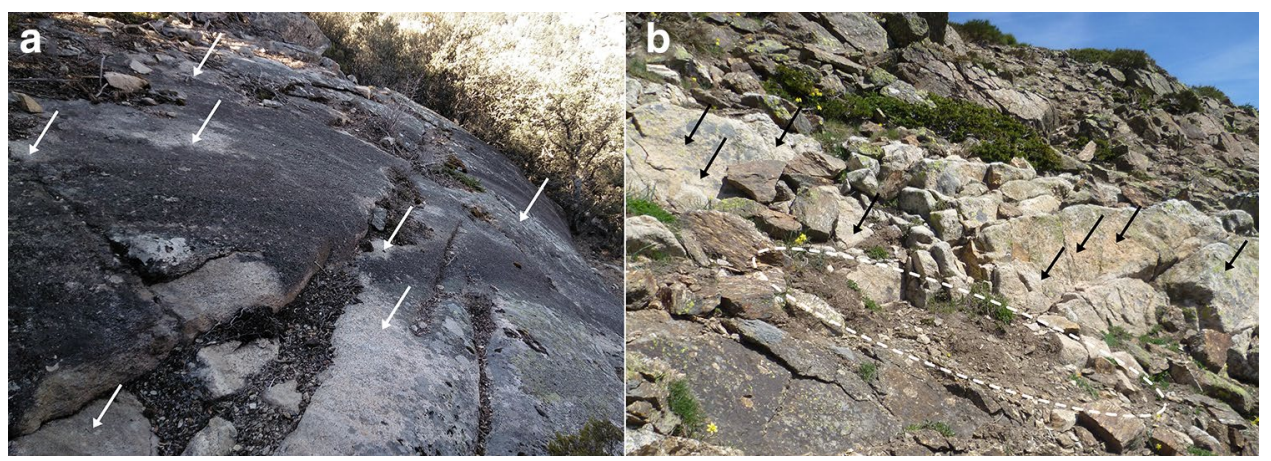

Fig. 4 a Granitoid domic surface at steep slope area. Moss disappearance reduces rock rugosity, facilitating diverse size particle movement. Overgrazing contributes to soil and vegetation loss, observable at rock cracks. Runoff at rainy periods accelerates hillside erosion around the outcrop. b Gneiss rocky ground at high mountain areas

\section{Screes (S)}

This term refers to the accumulation of rocks on mountain slopes (Fig. 4b). These screes form due to the breakup of rocks forming the mountain peaks, which fall and move down the slopes. These are frequent in the high mountain zone of the Sierra de Guadarrama (Palacios et al. 2003; Carrasco et al. 2016). The rock fragment sizes in screes vary from a few centimeters to more than $1 \mathrm{~m}$ long.

\section{Mixed terrain of loose materials and rocks (M)}

Rock outcrops and loose materials are combined (Scarciglia et al. 2007; Lucía et al. 2011). This is the commonest scenario at Sierra de Guadarrama. This scenario clearly shows the relationship between rock moss loss and erosion processes surroundings outcrops with runnels, gullies, or mass material movements.

Altitude must be considered while assessing im. Above $2100 \mathrm{~m}$, moss presence is naturally less frequent than lower down, making this indicator more difficult to apply. Above $2000 \mathrm{~m}$, accumulated winter snow persists for several months, frequently making it hard for mosses to develop (Palacios and García 1997).

Another factor to consider is rock type. In the ridge area of the SGNP, granites and gneisses alternate. Gneisses have a more irregular surface texture where the moss cover is also more irregular than on granitic surfaces. That is why granitic outcrops are recommended for data collection and indicator analysis.

In this sense, Pedriza de Manzanares is the area where this indicator is most easily and suitably applied in the SGNP because of the high frequency of granites and rock outcrops, as both rock faces and isolated blocks.

Regarding the Iberian wild goat factor, several considerations must be noted. In those areas of the Sierra de
$(2000 \mathrm{~m})$. Moss elimination from rock and soil favors rock block unearthing and unconsolidated material erosion. Arrows indicate moss elimination in overgrazing areas in both pictures (a and $\mathbf{b})$. Dotted oval (photo b) indicates an area of strong erosion, wild goat browsing, and abundance of pellets

Guadarrama without Iberian wild goats, rock moss cover is virtually complete (Lara et al. 2005; García-Rodríguez 2019). Moss loss may be caused by long dry periods. Nevertheless, it was shown that moss cover does not show significant losses in areas without Iberian wild goat, even when south facing, at altitudes under $900 \mathrm{~m}$, and subject to high temperature and low rainfall. This provides a baseline before the impact of the reintroduction of the Iberian wild goat.

To link moss loss with Iberian wild goat pressure, a series of requirements are needed: (a) identify similar rocks areas that are accessible and inaccessible of Iberian wild goat, which effectively justify moss presence, (b) presence of browsing evidence on woody and herbaceous plant species, and (c) presence of Iberian wild goat excrement in the area.

This indicator can be applied to any rock accessible to Iberian wild goat and with moss cover. This includes the three geomorphological scenarios described above.

\section{Data collection}

A total of 95 different points were selected for this study (Table 1), distributed in areas of the SGNP with different abundance of Iberian wild goat (Refoyo et al. 2019).

At each selected point, $300 \mathrm{~m}^{2}$ of rock surface was surveyed. When rock outcrops were smaller, a series of dispersed outcrops were surveyed until this total surface area was reached. The presence of Iberian wild goat at each of these 95 survey points was determined following Perea et al. (2015), where wild goat droppings, pellet groups ( $p g$ ), were counted at each point corresponding to a sampling area of $314 \mathrm{~m}^{2}$ (10-m-radius circle). The dropping counting surveys took place at the same location and during the same dates as the surveying for moss cover and rock erosion. The estimate of the habitat use, via counting of the groups of Iberian wild goat excrement $(\mathrm{pg})$, followed the procedures of Pfeifer et al. (1996) and Smart et al. (2004). Rock outcrop 
im measurements were done at the same surface where pellet groups were assessed. Quantification of the indicator was based on studying rock surface moss loss percentage. This moss-free surface was identified visually and quantified with the help of photographs. The im value for each selected point was averaged from the individual im values for that spot.

Based on the Iberian wild goat pressure, rock-type geomorphological scenarios, and altitude, eight types of zone were predefined to enable comparisons and validate the proposed indicator. These areas were, from low to high altitude: La Pedriza, Siete Picos, Navafría (East and West), Cuerda Larga (East and West), Bola del Mundo and Valdemartín, and Peñalara Massif (Table 2).

\section{Statistics and data analysis}

The following tools were employed for data analysis: Python, version 3.7.3.; Anaconda client, version 1.7.2.; Conda, version 4.7.5.; Jupyter, version 1.0.0.; Jupyter client, version 5.2.4.; IPython, version 7.4.0.; Numpy, version 1.18.2.; Scipy, version 1.2.1.; Pandas, version 0.24.2.; Matplotlib, version 3.1.1.

The approach encompassed both data analysis and statistical analysis. Classical statistics and newer data science techniques were used for either data exploration or hypothesis testing. This focus is supported by both a proposal of systemization (Karpatne et al. 2017), and its application in several scientific fields such as geology (García-Rodríguez et al. 2015), psychology (Manzanero et al. 2019), and education (Aroztegui Vélez, et al. 2020). The specific techniques used were: (a) exploratory data analysis, (b) scatter plots, (c) box plots, (d) class I analysis of variance (ANOVA), (e) null hypothesis significance test ( $p$-value) of ANOVA results, (f) coefficient of determination, used as an effect size measurement, (g) null hypothesis significance test ( $p$-value) linked to coefficient of determination results, (h) least-squares function fit. The curve fit function from the scipy.optimize library was used for function adjustments. The curve_fit function uses the squared minima procedure as detailed by Branch et al. (1999), (i) the goodness of fit function for the data through the coefficient of determination, and (j) graphical representation of functions.

Scatter plots show the values and distribution of the raw data collected. Some key data distribution patterns are only accessible through these types of analyses, as has been known for a long time (Anscombe 1973). Awareness of their relevance has continued to grow over time (Matejka and Fitzmaurice 2017).

Class I analysis of variance was used to test hypotheses concerning statistically significant differences between groups being compared. Analysis of variance is a relatively robust technique even in the face of noncompliance of its assumptions, including both a normal distribution (Blanca et al. 2017) and homoscedasticity (Kohr and Games 2014). It is selected, given its clarity, even in cases where all these assumptions are not met.

\section{Results and discussion}

The results are presented below after the hypotheses to be tested on the statistical behavior of the im indicator.

The box plot in Fig. 5 shows descriptive statistics of data groupings. Median values of $i m$ for the Cuerda Larga West and La Pedriza areas are notably higher than those for Siete Picos or Peñalara Massif. The variation is also shown by the graphical representation of interquartile range and extremes (Fig. 5). In this sense, the variability is greater at Cuerda Larga East and lesser at Peñalara Massif or Siete Picos. Intermediate values were found at the Bola del Mundo and La Pedriza areas. However, the interquartile variability may be an inadequate representation of average variability. Data variability at Siete Picos or Peñalara Massif, with low im values, overlaps little with those of high im values. These results make sense if the particularities of each area are taken into account. Iberian
Table 2 Description of study areas according to Iberian wild goat presence and pressure, rock type, geomorphological scenario, and altitude

\begin{tabular}{lllll}
\hline Zone & $\begin{array}{l}\text { Iberian wild goat } \\
\text { presence/pressure }\end{array}$ & Rock type & $\begin{array}{l}\text { Geomorphologi- } \\
\text { cal scenarios }\end{array}$ & Altitude (m.a.s.1.) \\
\hline La Pedriza & Yes/High & Granites & R & 1400 (900-1700) \\
Siete Picos & No/- & Granites and gneisses & M, R & 1800 \\
Navafría East & No/- & Granites and gneisses & M, R & 1900 \\
Navafría West & Yes/Low & Granites and gneisses & M, S, R & 2000 \\
Cuerda Larga East & Yes/High & Granites and gneisses & M, S, R & 1900 \\
Cuerda Larga West & Yes/High & Granites and gneisses & M, S, R & 2100 \\
Bola del Mundo and & Yes/High & Granites and gneisses & M, S, R & 2000 \\
Valdemartín & & Gneisses & M, S, R & 2200 (peak 2428) \\
Peñalara Massif & Yes/Low & & & \\
\hline
\end{tabular}

M, mixed terrain with loose materials and rocks; $\mathrm{S}$, screes; R, rock outcrops 


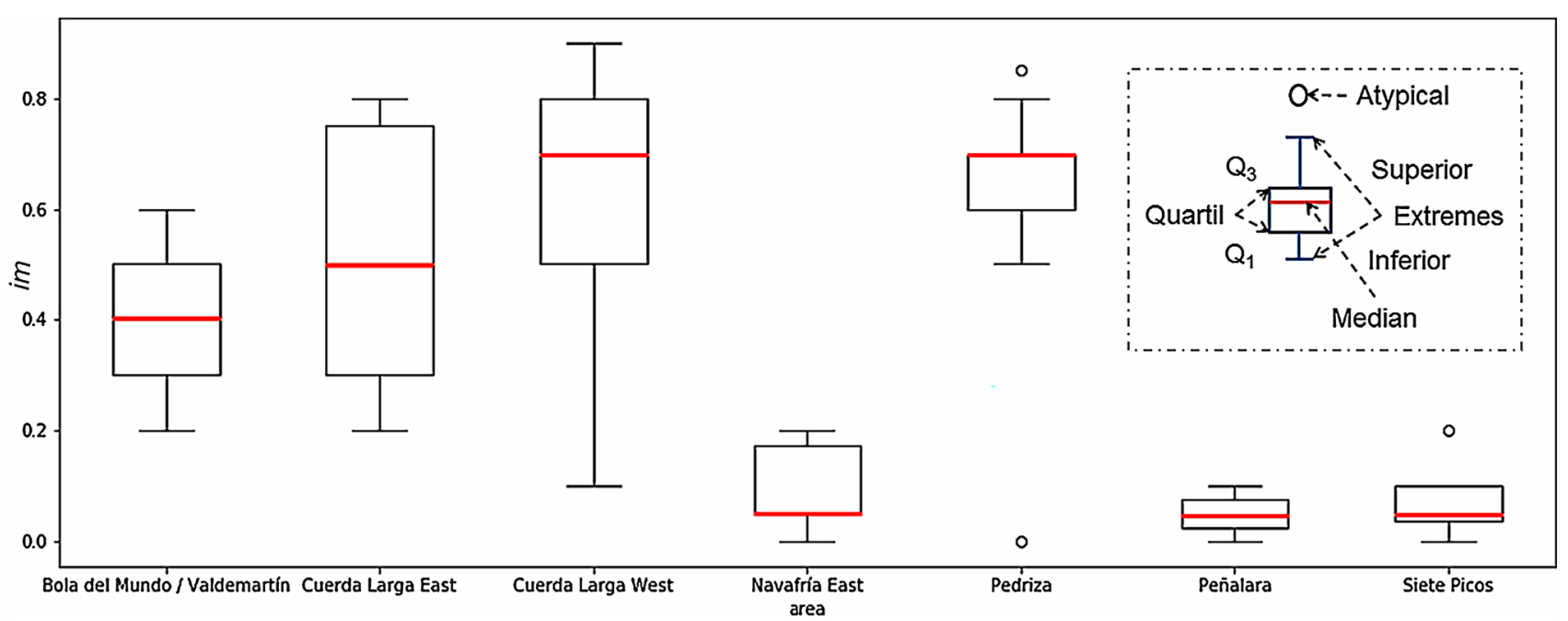

Fig. 5 Data value distribution by location group. Box plot of $i m$ by SGNP area

wild goat presence has not been recorded at Navafría East and Siete Picos, in line with Refoyo et al. (2019), and the Peñalara peak is situated at an altitude of $2428 \mathrm{~m}$, with wild goat presence but snow cover for 7-8 months a year.

The descriptive data in Table 3 include the number of measurements $(n)$ in each area. The average im measurements at Cuerda Larga West and La Pedriza are clearly higher than at Siete Picos. Again, the variability shown through nominal values (such as in Fig. 5) appears different from the variability coming from all the data, as for the standard deviation. In the latter case, the variability at both Cuerda Larga West and La Pedriza is greater and more similar to each other than appeared to be the case indicated by the interquartile range. The standard deviation is notably less at Siete Picos and Peñalara. The obtained data are consistent with previous studies on the presence of the Iberian wild goat (Refoyo et al. 2015), which previously identified Cuerda Larga West and La Pedriza as locations with the greatest historical presence of the species (PNSG 2020).

\section{The im indicator will distinguish between areas with different lberian wild goat grazing pressure}

The proposed indicator would not be useful if it failed to identify differences between areas where they exist. Consequently, this test is interesting as it indicates whether im will be useful in studies and monitoring projects for discriminating areas with different levels of Iberian wild goat browsing pressure. Similarly, it should not show statistically significant differences between similar areas.

The location groups (LG) 0 and LG 3 (see the groupings in the header of Table 4) show low im levels, while LG 1 and LG 2 show high im levels. Comparisons of LG 0 compared with LG 1 and LG 2 (first and second rows in Table 4) show statistically significant differences. When comparing LG 0 and LG 3, no statistically significant differences were found. Consequently, the im indicator shows the desired characteristics. Therefore, its statistical behavior is useful to indicate areas with different environmental pressure due to Iberian wild goat presence. It should be remembered that

Table 3 Descriptive statistics of $i m$ values in SGNP areas

\begin{tabular}{|c|c|c|c|c|c|c|c|}
\hline Indicator & $\begin{array}{l}\text { Bola del Mundo and } \\
\text { Valdemartín }\end{array}$ & $\begin{array}{l}\text { Cuerda } \\
\text { Larga East }\end{array}$ & $\begin{array}{l}\text { Cuerda Larga } \\
\text { West }\end{array}$ & Navafría East & La Pedriza & $\begin{array}{l}\text { Peñalara and } \\
\text { Navafría West }\end{array}$ & Siete Picos \\
\hline$n$ & 2 & 7 & 9 & 10 & 10 & 2 & 12 \\
\hline Average & 0.40 & 0.51 & 0.60 & 0.09 & 0.61 & 0.05 & 0.07 \\
\hline Standard deviation & 0.28 & 0.26 & 0.25 & 0.08 & 0.24 & 0.07 & 0.06 \\
\hline Minimum & 0.20 & 0.20 & 0.10 & 0.00 & 0.00 & 0.00 & 0.00 \\
\hline$Q_{1}(25 \%)$ & 0.30 & 0.30 & 0.50 & 0.05 & 0.60 & 0.02 & 0.04 \\
\hline$Q_{2}(50 \%)$ & 0.40 & 0.50 & 0.70 & 0.05 & 0.70 & 0.05 & 0.05 \\
\hline$Q_{3}(75 \%)$ & 0.50 & 0.75 & 0.80 & 0.17 & 0.70 & 0.07 & 0.10 \\
\hline Maximum & 0.60 & 0.80 & 0.90 & 0.20 & 0.85 & 0.10 & 0.20 \\
\hline
\end{tabular}


Table 4 Statistically significant differences (ANOVA) of $i m$ comparing different location groups in the SGNP

\begin{tabular}{llllllll}
\hline Indicator & LG $(0)$ & LG $(1,2,3)$ & $F$ & $\begin{array}{l}p \\
\text { ANOVA }\end{array}$ & $\begin{array}{l}\text { Statistically } \\
\text { significant differ- } \\
\text { ences? }\end{array}$ & $\begin{array}{l}\text { Average } \\
\text { reference } \\
\text { site }\end{array}$ & $\begin{array}{l}\text { Average } \\
\text { other } \\
\text { site }\end{array}$ \\
\hline$i m$ & 0 & 1 & $F(1,39)=157.000$ & 0.000 & Yes & 0.077 & 0.661 \\
$i m$ & 0 & 2 & $F(1,29)=36.827$ & 0.000 & Yes & 0.077 & 0.378 \\
$i m$ & 0 & 3 & $F(1,22)=0.289$ & 0.596 & No & 0.077 & 0.050 \\
\hline
\end{tabular}

Location group 0: Siete Picos + Navafría East. Location group 1: Pedriza + part of Cuerda Larga East + part of Cuerda Larga West. Location group 2: part of Cuerda Larga East + part of Cuerda Larga West + Bola del Mundo/Valdemartín. Location group 3: Peñalara + Navafría West
LG 0 includes all SGNP areas where Iberian wild goat has not been recorded. On the other hand, the sites within LG 3 are located between 2000 and $2400 \mathrm{~m}$ in altitude. As mentioned above, LG 3 has snow cover for most of the year and represents a limitation of the model as mosses at such elevation are rare. Additionally, the historical presence of the Iberian wild goat in LG 3 is seasonal (in summer) and only over the last 10 years (Refoyo et al. 2019). At LG 2, an area with similar altitudes (Cuerda Larga West and East), permanent Iberian wild goat presence has been described for at least the past 12 years (Refoyo et al. 2019). In spite of the high altitude, it was possible to measure the im indicator in LG 2 at some points. The results support the hypothesis. The im indicator is able to distinguish between areas with different environmental pressure.

\section{The im indicator will show a high proportion of explained variance between areas with different browsing pressure}

This hypothesis was tested through effect size calculations.

In addition to encountering different browsing pressure levels, it is important to evaluate the size of these differences. Given two areas with statistically significant differences, are these differences large or small? Effect size measurements allow one to test this hypothesis. The coefficient of determination, which equals the Pearson correlation squared, is used. Within each area group, the coefficient of determination is interpreted as the variance associated with the independent variable pellet group $(\mathrm{pg})$ and the dependent variable (im). In other words, it is interpreted as the proportion of the variation expected in $i m$, knowing the variation in $p g$. The results indicate that $80 \%$ and $56 \%$ of the associated variance was explained when considering areas with high (LG 1 and LG 2) and low (LG 0) browsing pressure (Table 5). Moreover, the probability that the value obtained was by change is sufficiently low $(p<0.001)$. This suggests that, if $p g$ causes $i m$, the environmental factors that produce variations of $p g$ levels will produce considerable variations in the levels of browsing pressure on mosses.

Comparing the two areas with low browsing pressure (LG 0 and LG 3), the variance observed is negligible. This result, combined with the preceding ones, shows that the im indicator is useful to obtain these parameters. At the theoretical level, the effect size indicates which variables have greatest effect, being more relevant for moss loss evaluation. For an applied set, this information is useful to help decide which variables act to maximize the desired effect. The geological and population arguments that explain the results are the same as those given for the previous hypothesis. Finally, im indicator measurements showed high proportion of variance for areas with different browsing levels. Again, these results support the stated hypothesis.

\section{A functional relationship to explain and predict Iberian wild goat pressure can be established}

To test this hypothesis, we fit a function to the cloud of data with two possible functional relationships: linear and parabolic (Fig. 6a).

The diagram shows that the $i m$ values increase as $p g$ values get larger. Different degrees of $i m$ variability exist at different
Table 5 Effect size of $i m$ values comparing different location groups in SGNP

\begin{tabular}{lllllll}
\hline Indicator & LG $(0)$ & LG $(1,2,3)$ & $r^{2}$ & $\begin{array}{l}\text { Associated } \\
\text { variance }\end{array}$ & $\begin{array}{l}r^{2} \\
\text { Prob. of ran- } \\
\text { dom associated } \\
\text { variance }\end{array}$ \\
\hline$i m$ & 0 & 1 & 0.801 & high & 0.000 & NO \\
$i m$ & 0 & 2 & 0.559 & high & 0.000 & NO \\
$i m$ & 0 & 3 & 0.013 & none & 0.596 & YES \\
\hline
\end{tabular}

Location group 0: Siete Picos + Navafría East. Location group 1: Pedriza + part of Cuerda Larga East + part of Cuerda Larga West. Location group 2: part of Cuerda Larga East + part of Cuerda Larga West + Bola del Mundo/Valdemartín. Location group 3: Peñalara + Navafría West 

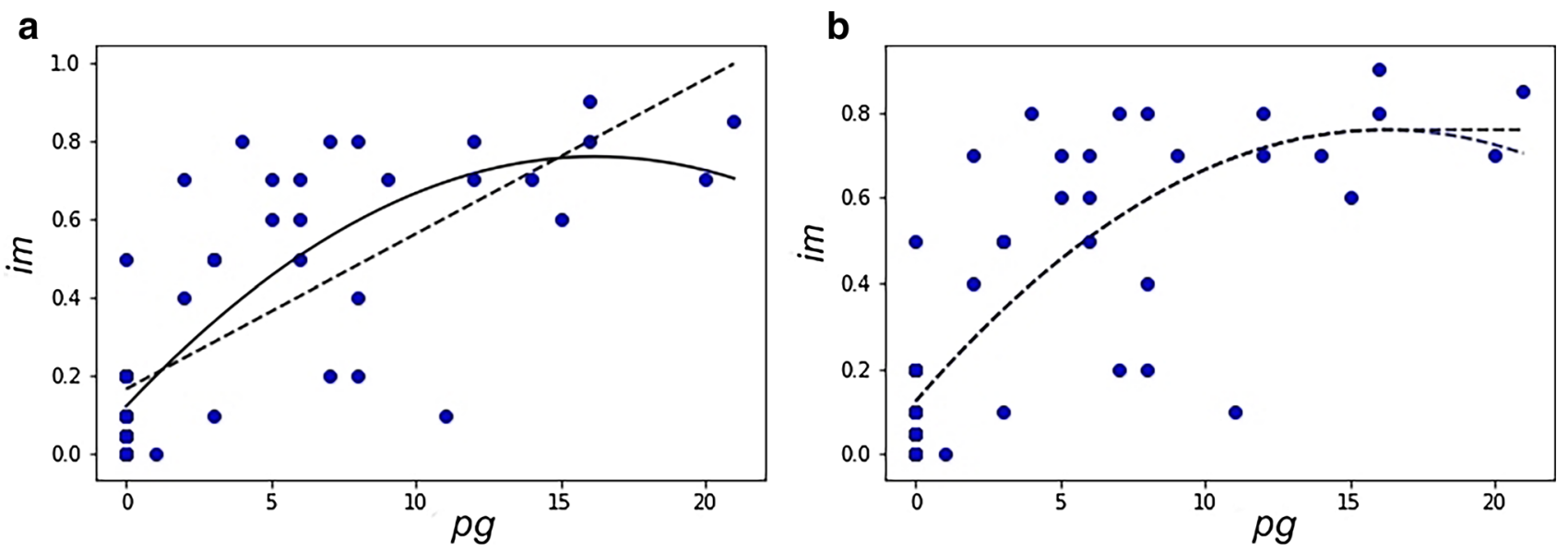

Fig. 6 Fit using several functions of im indicator dependent on Iberian wild goat pressure ( $\mathrm{pg}$ ). a Comparison of degree 1 and 2 polynomial functions. b Comparison of degree 2 polynomial function and degree 2 polynomial adjusted function

$p g$ values. The $i m$ variability is higher at low $p g$ values. As $p g$ grows, $i m$ increases. The $i m$ values grow more at low $p g$ levels, making $i m$ stabilize for greater $p g$ values, approaching an asymptote. This may be explained by the lower availability of the food resource (moss) at high $p g$ values.

The parabolic function $\left(r^{2}=0.630\right)$ achieves a closer fit to data than the linear one $\left(r^{2}=0.558\right)$. This adjustment represents a 7.75\% improvement, indicating a preferable model. According to this model, an increase in Iberian wild goat presence will lead to an increase in browsing pressure on the mosses. The increase in impact gradually reduces as Iberian wild goat pressure increases, until it reaches a maximum impact level (Fig. 6b) beyond which it does not increase further. However, the parabolic curve suggests a reduction in browsing pressure after reaching this maximum level, which appears to be incorrect. In a proper model, once achieved, the maximum level is maintained. This function, a parabolic curve with a horizontal straight line to the right (Fig. 6b), provides a slightly improved fit to data $\left(r^{2}=0.632\right)$. It is also a theoretical model that is more coherent with the process of browsing pressure itself.

The parabolic function obtained was as follows:

$i m(p g)=0.123+0.078 p g-0.002 p g^{2}$

The value of the $i m(p g)$ function at its maximum is

$\operatorname{im}(16.211)=0.759$

Subsequently, the parabolic curve with a straight horizontal line to the right, which we define as adjusted im, $\operatorname{im}_{a d}(p g)$, is represented as follows:

$\operatorname{im}_{\mathrm{ad}}(p g)=\left\{\begin{array}{cc}\operatorname{im}(p g) \text { if } p g<16.211 \\ 0.759 \quad \text { otherwise }\end{array}\right.$
This allows one to understand the precise nature of the relationship between Iberian wild goat presence and the pressure exerted on the mosses. This relationship is a direct but nonlinear proportional relationship between im and $\mathrm{pg}$. It has a greater increase at low values and a smaller increase at higher ones, revealing great sensitivity of mosses to small changes in wild goat pressure at lower pressure values.

Effectively, the function defined provides knowledge regarding the increase of $\mathrm{im}$ as a function of the Iberian wild goat population, facilitating comparisons between sites or within sites over different time periods. To illustrate its possible use in research or for monitoring, we take for instance two hypothetical SGNP sites, A and B, yielding Iberian wild goat pressure values of $p g_{\mathrm{A}}=2$ and $p g_{\mathrm{B}}=8$. The $i m$ values and the percentage increase of $i m$ in area $\mathrm{B}$ compared with A would then be calculated as follows:

In both cases, $p g<16.211$, so

$i m_{\mathrm{ad}}\left(p g_{\mathrm{A}}\right)=i m_{\mathrm{ad}}(2)=0.123+0.078 \cdot 2-0.002 \cdot 2^{2}=0.271$

$i m_{\mathrm{ad}}\left(p g_{\mathrm{B}}\right)=i m_{\mathrm{ad}}(8)=0.123+0.078 \cdot 8-0.002 \cdot 8^{2}=0.619$

After obtaining the $i m_{\mathrm{ad}}$ values for both areas, the percentage increase in area B compared with area A is calculated as follows:

$\left|i m_{\mathrm{ad}}\left(p g_{\mathrm{A}}\right)-i m_{\mathrm{ad}}\left(p g_{\mathrm{B}}\right)\right|=|0.271-0.619|=0.348$

$$
\frac{\left|i m_{\mathrm{ad}}\left(p g_{\mathrm{A}}\right)-i m_{\mathrm{ad}}\left(p g_{\mathrm{B}}\right)\right|}{i m_{\mathrm{ad}}\left(p g_{\mathrm{A}}\right)} \times 100=\frac{0.348}{0.271} \times 100=128.41 \%
$$


If the two measurements in the same area refer to different times, with A the first and B the second, the $128.41 \%$ result obtained would represent the magnitude of the worsening of the situation between the two measurements.

Returning to environmental considerations, when im values are low, moss abundance is high, attracting high number of individuals. As the availability of food resources diminishes, the Iberian wild goat populations move away (Martínez 1992) to other less exploited areas, possibly leaving some moss patches unbrowsed/untrampled, corresponding to the highest im values.

Once the highest im value is reached (near to 1), the maximum moss impact is linked to the goats moving to a different browsing area. In this sense, the application of the indicator is very relevant to establish a relationship ranging from a null pressure level, without Iberian wild goats, to values close to its maximum (over 0.76). The maximum impact occurs in areas where the overpopulation of Iberian wild goat is five times more than the carrying capacity (Perea et al. 2015). Iberian wild goat population above this size is not reflected by greater $i m$ values. On the other hand, Iberian wild goat population reduction, either from natural causes or environmental management techniques, does not change im until the Iberian wild goat population falls below this maximum impact level. Once that level of population reduction is reached, we would expect moss cover to start recovering, with im values decreasing. Further studies should analyze the ability of mosses to recover after significant loss and the time elapsed to fully recover the lost area.

\section{Conclusions}

Over the last 25 years, large areas of the Sierra de Guadarrama have suffered from serious erosion problems (GarcíaRodríguez 2015, 2018). This is caused by natural processes, anthropic activities related to the management of protected areas, mass sporting activities, and overgrazing and/or trampling by the Iberian wild goat and other livestock species (PNSG 2020).

An indicator relating the environmental pressure exerted by Iberian wild goat on moss cover was proposed and named $i m$. This indicator allows an estimation of the wild goat pressure in different areas, as well as comparisons between different areas or changes in pressure at the same site over time. This can be useful to characterize and monitor natural areas, through impact maps and environmental management measures. The im indicator may thus be used with management measures that aim to control the Iberian wild goat population and its impact. Efficient management would enable the detection of reductions in $i m$ values, indicating a reduction in environmental pressure, potentially associated with a reduction in browsing and/or trampling. This will favor vegetation recovery and a reduction in soil erosion (intensity and speed).

The validation process of the im indicator confirmed its usefulness to observe the pattern of distribution, progress, nonlinearity, and variability in nonaggregated and descriptively aggregated data. It also enabled the detection of environmental pressure exerted by Iberian wild goat across different areas (ANOVA), to assess the magnitude of Iberian wild goat pressure exerted on mosses (associated variance through coefficient of determination), which was very high in the studied areas. Additionally, the proposed mathematical function allowed the discovery of the relationship between Iberian wild goat pressure and $i m$ variation dynamics. This function is also found to be highly useful for evaluating spatiotemporal changes in the impact of wild goat on moss cover and, thus, by extension, for monitoring and managing rocky areas dominated by large herbivores.

Moss cover disappearance is a good indicator of environmental pressure, linked to biodiversity loss and eroded areas where the superficial organic layer has been eliminated. Observations in areas with high im levels show common processes and effects during the last decade: (a) soil and vegetation elimination in open cracks in large rock outcrops, (b) unearthing and exposure of the rock base where moss has been lost (Centeno and García-Rodríguez 2008; García-Rodríguez 2015), (c) unearthing and exposure of tree roots in the surroundings of rock outcrops with severe damage to or complete elimination of trees and shrubs growing in the rock cracks (García-Rodríguez 2018), (d) browsing and elimination of woody plants, scrubs, and trees (Perea et al. 2015), (e) soil erosion leading to runnels and gullies (Pedraza et al. 2014; García-Rodríguez 2015), (f) mass movement of silts, sands, and even loose rocks at rocky outcrop surfaces (Centeno 1989; Palacios et al. 2003; García-Rodríguez 2019), and ( $\mathrm{g}$ ) general loss of biodiversity dependent on organic soils (Centeno and García-Rodríguez 2008).

These results indicate severe erosion over large areas of the SGNP, with differing final conditions depending on the Iberian wild goat pressure and specific geomorphological features of each site.

The im indicator presents high values in areas formed by rocky outcrops and where food sources are scarce or have disappeared.

The negative impacts of overgrazing and trampling typically increase during drought periods as food availability decreases. Iberian wild goat is probably the wild ungulate best adapted to rock outcrops, even in dry areas (PascualRico et al. 2020). Under the current context of climate change, with increasing duration and intensity of drought periods (IPCC 2021), the vulnerability of soils and mosses to wild ungulates is expected to increase. This study suggests that Iberian wild goat overpopulation is probably the main 
erosive agent in the SGNP in mid and high mountain areas. Population control of this species is essential to reduce soil and biodiversity loss in this highly valuable national park (PNSG 2020).

Acknowledgements The fieldwork was undertaken in collaboration with specialists of the Centro de Investigación del Parque Nacional, Facultad de Ciencias Biológicas of Universidad Complutense de Madrid (UCM), and Escuela Técnica Superior de Ingeniería de Montes, Forestal y del Medio Natural of Universidad Politécnica de Madrid (UPM). The authors gratefully thank John L. Muddeman, biologist, guide, and nature interpreter, for its English technical translation.

Funding Open Access funding provided thanks to the CRUE-CSIC agreement with Springer Nature. This work has been carried out within the framework of an agreement between the two Universities [Universidad Nacional de Educación a Distancia (UNED), the Universidad Politécnica de Madrid (UPM)], and Sierra de Guadarrama National Park (SGNP). R.P. and M.G.R. acknowledge financial support from the Madrid Regional Government and Consejería de Medio Ambiente through the "Selección de indicadores ambientales y poblacionales para la elaboración de un plan de gestión de la Cabra Montés en el Parque Nacional Sierra de Guadarrama” project.

\section{Declarations}

Conflicts of interest On behalf of all authors, M.G.R. states that there are no conflicts of interest.

Open Access This article is licensed under a Creative Commons Attribution 4.0 International License, which permits use, sharing, adaptation, distribution and reproduction in any medium or format, as long as you give appropriate credit to the original author(s) and the source, provide a link to the Creative Commons licence, and indicate if changes were made. The images or other third party material in this article are included in the article's Creative Commons licence, unless indicated otherwise in a credit line to the material. If material is not included in the article's Creative Commons licence and your intended use is not permitted by statutory regulation or exceeds the permitted use, you will need to obtain permission directly from the copyright holder. To view a copy of this licence, visit http://creativecommons.org/licenses/by/4.0/.

\section{References}

Anscombe FJ (1973) Graphs in statistical analysis. Am Stat 27:17-21. https://doi.org/10.2307/2682899

Armstrong DP, Seddon PJ (2008) Directions in reintroduction biology. Trends Ecol Evol 23:20-25. https://doi.org/10.1016/j.tree. 2007.10.003

Aroztegui Vélez J, Iglesias Soilán M, Fernández J (2020) SimGuide. Una arquitectura de programas de intervención educativa para el desarrollo del pensamiento formal. In: Gázquez Linares JJ, Molero Jurado MM, Martos Martínez A, Barragán Martín AB, Simón Márquez MM, Sisto M, Salvador RMP and Tortosa Martínez BM (eds) Investigación en el ámbito escolar. Nuevas realidades en un acercamiento multidimensional a las variables psicológicas y educativas. Tomo IV, pp 1303-1318. Dykinson, Madrid

Blanca MJ, Alarcón R, Arnau J, Bono R, Bendayan R (2017) Non-normal data: Is ANOVA still a valid option? Psicothema 29:552-557. https://doi.org/10.7334/psicothema2016.383
Blanco Castro JE, Acón Remacha M (1984) Hepáticas de La Pedriza. Anal Biol Facult Biol Univ Murcia 2:209-214

Branch MA, Coleman TF, Li Y (1999) A subspace, interior, and conjugate gradient method for large-scale bound-constrained minimization problems. SIAM J Sci Comput 21:1-23. https://doi.org/10. 1137/S1064827595289108

Carrasco RM, Pedraza J, Willenbring JK, Karampaglidis T, Soteres RL, Martín-Duque JF (2016) Morphology of Los Pelados-El Nevero Massif (Sierra de Guadarrama National Park). A new interpretation and chronology. Bolet Real Soc Española Hist Natural Secc Geol 110:49-64

Centeno JD (1989) Evolución cuaternaria de la vertiente sur del sistema central español. Las formas residuales como indicadoras morfológicas. Cadernos Lab Xeol Laxe 13:79-88

Centeno-Carrillo JD, García-Rodríguez M (2008) Balance hídrico de las superficies grabadas en rocas graníticas. Un modelo geomorfológico e hidrogeológico con implicaciones ambientales. Tecnol Desarrollo 6:1-22

Comunidad de Madrid (2010) Atlas. El Medio Ambiente en la Comunidad de Madrid. Consejería de Medio Ambiente y Ordenación del Territorio, $\mathrm{p} 83$

Concostrina-Zubiri L, Huber-Sannwald E, Martínez I, Flores JF, ReyesAgüero JA, Escudero A, Belnap J (2014) Biological soil crusts across disturbance-recovery scenarios: effect of grazing regime on community dynamics. Ecol Appl 24:1863-1877

Concostrina-Zubiri L, Molla I, Velizarova E, Branquinho C (2017) Grazing or not grazing: implications for ecosystem services provided by biocrusts in Mediterranean cork oak woodlands. Land Degrad Dev 28(4):1345-1353

Dale VH, Beyeler SC (2001) Challenges in the development and use of ecological indicators. Ecol Ind 1:3-10

Evans R (1996) Some impacts of overgrazing by reindeer in Finnmark. Norway Rangifer 16(1):3-19

Fandos P, Espada T, Barcena S, Granados JE, Burón D (2010) Resultados de los muestreos sobre cabra montés (Capra pyrenaica) en Andalucía. Informe Anual 2010: Junta de Andalucía, Consejería de Medio Ambiente, Sevilla, Spain, p 95

Gaillard, JM., Duncan P, Van Wieren SE, Loison A, Klein F, Maillard D (2008) Managing large herbivores in theory and practice: is the game the same for browsing and grazing species. In: The ecology of browsing and grazing (pp 293-307). Springer, Berlin, Heidelberg

García-Rodríguez M (2015) Erosión y exhumación de bloques graníticos en la Pedriza del Manzanares (España). Evolución histórica a partir de dataciones relativas. Rev Mexicana Ciencias Geol 32(3):492-500

García-Rodríguez M (2018) Erosión y pérdida de suelo en la Pedriza de Manzanares (Parque Nacional Sierra de Guadarrama). Revista 11:53-60

García-Rodríguez M, Gomez-Heras M, Alvarez de Buergo M, Fort M, Aroztegui J (2015) Polygonal cracking associated to vertical and subvertical fracture surfaces in granite (La Pedriza del Manzanares, Spain): considerations for a morphological classification. J Iber Geol 41(3):365-383. https://doi.org/10.5209/rev_ JIGE.2015.v41.n3.48860

García-Rodríguez M, Sánchez-Jiménez A, Murciano A, Pérez-Uz B, Martín-Cereceda M (2017) Influencia de la temperatura sobre la asimetría de pilancones en ambiente granítico. Aplicación de un modelo de regresión lineal. Bol Soc Geol Mexicana 69(2):479_ 494. https://doi.org/10.18268/BSGM2017v69n2a11

García-Rodríguez M (2019) Problemática ecológica. Erosión y pérdida de biodiversidad. In: La Pedriza. Geología y escalada, Ed. Cordillera Cantábrica, pp 82-99

Hui C (2006) Carrying capacity, population equilibrium, and envrionment's maximal load. Ecol Model J 192:317-320. https://doi.org/ 10.1016/j.ecolmodel.2005.07.001 
IPCC (2021) Climate change 2021: the physical science basis. In: Masson-Delmotte VP, Zhai A, Pirani SL, Connors C, Péan S, Berger N, Caud Y, Chen L, Goldfarb MI, Gomis M, Huang K, Leitzell E, Lonnoy JBR, Matthews TK, Maycock T, Waterfield O, Yelekçi R, Zhou Y, Zhou B (eds) Contribution of working group i to the sixth assessment report of the intergovernmental panel on climate change. Cambridge University Press (In Press)

Izquierdo JL (2007) Cartografía de la vegetación del Parque Natural de Peñalara y su zona periférica de protección: Una herramienta para la gestión. En: V Jornadas Científicas del Parque Nacional de Peñalara y del Valle del Paular. Comun Madrid 2007:83-92

Karpatne A, Atluri G, Faghmous JH, Steinbach M, Banerjee A, Ganguly A, Shekhar S, Samatova N, Kumar V (2017) Theory-guided data science: a new paradigm for scientific discovery from data. IEEE Trans Knowl Data Eng 29(10):2318-2331. https://doi.org/ 10.1109/TKDE.2017.2720168

Kohr RL, Games PA (2014) Robustness of the Analysis of Variance, the Welch Procedure and a Box Procedure to Heterogeneous Variances. J Exp Educ 43:61-69. https://doi.org/10.1080/00220973. 1974.10806305

Lara F, Albertos B, Garilleti R, Mazimpaka V (2005) El estado de conocimiento y la conservación de los briófitos de la Comunidad de Madrid (España); interpretación actual a partir del caso de los musgos. Bol Soc Española Briol 26(27):33-45

Lucia A, Laronne JB, Martín-Duque JF (2011) Geodynamic processes on sandy slope gullies in central Spain field observations, methods and measurements in a singular system. Geodin Acta 24(2):61-79. https://doi.org/10.3166/ga.24.61-79

Luna J, Estébanez B (2008) Brioflora de Valsaín (Segovia): catálogo y observaciones corológicas. Bol Soc Española Briol 32(33):9-19

Manzanero AL, Scott MT, Vallet R, Aróztegui J, Bull R (2019) Criteria-based content analysis in true and simulated victims with intellectual disability. Anuario Psicol Jurídica 29(1):55-60

Marozas V, Pételis K, Brazaitis G, Baranauskaité J (2009) Early changes of ground vegetation in fallow deer enclosure. Balt for 15(2):268-272

Martínez T (1992) Estrategia alimentaria de la Cabra Montés (Capra pyrenaica) y sus relaciones tróficas con los ungulados silvestres y domésticos en Sierra Nevada, Sierra de Gredos y Sierra de Cazorla. In: Tesis Doctoral, Facultad de Ciencias Biológicas, Universidad Complutense de Madrid, p 521

Matejka J, Fitzmaurice G (2017) Same stats different graphs: generating datasets with varied appearance and identical statistics through simulated annealing. In: Proceedings of the $2017 \mathrm{CHI}$ conference on human factors in computing systems, pp 1290-1294. https:// doi.org/10.1145/3025453.3025912

Morales R (2003) Catálogo de plantas vasculares de la Comunidad de Madrid (España). Bot Complut 27:31-70. https://doi.org/10.1146/ annurev.ecolsys.31.1.367

Palacios D, García M (1997) The distribution of hight mountain vegetation in relation to snow cover. Peñalara, Spain. CATENA 30:1-40

Palacios D, de Andrés N, Luengo E (2003) Distribution and effectiveness of nivation in Mediterranean mountains. Peñalara (Spain). Geomorphology 54:157-178. https://doi.org/10.1016/S0169$555 \mathrm{X}(02) 00340-9$

Parque Nacional Sierra de Guadarrama (2020) Plan de gestión de las poblaciones de cabra montés en el Parque Nacional de la Sierra de Guadarrama: Informe Técnico, Comunidad de Madrid y Junta de Castilla y León, p 176

Pascual-Rico R, Sánchez-Zapata JA, Navarro J, Eguía S, Anadón JD, Botella F (2020) Ecological niche overlap between co-occurring native and exotic ungulates: Insights for a conservation conflict. Biol Invasions 22(8):2497-2508

Pedraza J, Carrasco MR, Domínguez-Villar D (2014) Geomorphology of la Pedriza Granitic Massif, Guadarrama Range. In: Gutiérrez F, Gutiérrez M (eds) Landscapes and landforms of Spain. Springer, The Netherlands, pp 71-81

Pedraza J (1978) Estudio geomorfológico de la zona de enlace entre las sierras de Gredos y Guadarrama (Sistema Central Español). In: Tesis Doctoral, Universidad Complutense de Madrid (UCM), p 432

Pegau RE (1970) Effect of reindeer trampling and grazing on lichens. J Range Manag 23(4):95-97. https://doi.org/10.2307/3896107

Peinado M, Fúster JM, Bellido F, Capote C, Casquet C, Navidad M, Villaseca C (1981) Caracteres generales del Cinturón Hercínico en el Sector Oriental del Sistema Central Español. Cuad Geol Ibérica 7:15-51

Perea R, Girardello M, San Miguel A (2014) Big game or big loss? High deer densities are threatening woody plant diversity and vegetation dynamics. Biodivers Conserv 23:1303-1318. https://doi. org/10.1007/s10531-014-0666-x

Perea R, García-Calvo R, Díaz-Ambrona C, San Miguel A (2015) The reintroduction of a flagship ungulate Capra pyrenaica; assessing sustainability by surveying woody vegetation. Biol Cons 181:917. https://doi.org/10.1016/j.biocon.2014.10.018

Pérez-Soba C, Villaseca C (2010) Petrogenesis of highly fractionated I-type peraluminous granites: La Pedriza pluton (Spanish Central System). Geol Acta 8:131-149. https://doi.org/10.1344/105. 000001527

Pfeifer D, Bäumer HP, Schleier U (1996) The “"minimal area”" problem in ecology; a spatial Poisson process approach. Comput Stat $11: 415-428$

Refoyo P, Olmedo C, Polo I, Fandos P, Muñoz B (2015) Demographic trends of a re-introduced Iberian Ibex Capra pyreniaca victoriae population in central Spain. Mammalia 79(2):139-145. https:// doi.org/10.1515/mammalia-2013-0141

Refoyo P, Olmedo C, Muñoz B, Horcajadas F, García M, Amigo JM, Martín S, Sanjuanbenito P (2019) Zonificación del Parque Nacional de la Sierra de Guadarrama según la presencia histórica de la cabra montés. Galemys 31:47-54. https://doi.org/10.7325/ Galemys.2019.A5

Rooney TP (2009) High white-tailed deer densities benefit graminoids and contribute to biotic homogenization of forest ground-layer vegetation. Plant Ecol 202:103-111. https://www.jstor.org/stable/ 40305685

Scarciglia F, Le Pera E, Critelli S (2007) The onset of the sedimentary cycle in a mid-latitude upland environment: weathering, pedogenesis and geomorphic processes on plutonic rocks (Sila Massif, Calabria). In: Arribas J, Critelli S, Johnsson MJ (eds) Sedimentary provenance and petrogenesis: perspectives from petrography and geochemistry. Geological Society of America Special Paper, vol 420, pp 149-166. https://doi.org/10.1130/2006.2420(10)

Smart JCR, Ward A, White PCL (2004) Monitoring woodland deer populations in the UK: an imprecise science. Mammal Rev 34:99 114. https://doi.org/10.1046/j.0305-1838.2003.00026.x

Stillman RA, Goss-Custard JD, Caldow RWG (1997) Modelling interference from basic foraging behavior. J Anim Ecol 66:692-703. https://doi.org/10.2307/5922

Vicente J, Ron E (1989) Contribución al conocimiento de la flora briológica de Canencia, Sierra de Guadarrama (Madrid). Bot Complut 14:75-85 